\title{
Haplotype analysis of the myotonic dystrophy type 1 (DM1) locus in Taiwan: implications for low prevalence and founder mutations of Taiwanese myotonic dystrophy type 1
}

\author{
Huichin $\operatorname{Pan}^{1}$, Her-Mau Lin ${ }^{2}$, Wei-Yao $\mathrm{Ku}^{1}$, Tung-Cheng $\mathrm{Li}^{2}$, Shuan-Yow $\mathrm{Li}^{1}$, \\ Chyi-Chyang Lin $^{1,3}$ and Kuang-Ming Hsiao*,1
}

${ }^{1}$ Department of Life Sciences, Chung Shan Medical and Dental College, Taiwan, Republic of China; ${ }^{2}$ Institute of Medicine, Chung Shan Medical and Dental College, Taichung, Taiwan, Republic of China; ${ }^{3}$ Department of Laboratory Medicine and Pathology, University of Alberta, Edmonton, Canada

Myotonic dystrophy type 1 (DM1) is an autosomal dominant neuromuscular disorder caused by a CTG trinucleotide expansion at the DM1 locus. In this study, we investigated the frequency distribution of various CTG repeats in normal alleles and haplotyped the normal and expanded DM1 locus in a group of Taiwanese people. In the 496 normal chromosomes examined, up to 18 alleles with different CTG lengths from 5 to 30 repeats were found and the frequency of $(\mathrm{CTG})>18$ alleles was only $1.4 \%(7 / 496)$, predicting a low prevalence of DM1. In addition, there is no absolute association between (CTG) $5_{-19}$ alleles and Alu insertion/deletion polymorphism observed on normal chromosomes. All DM1 alleles examined, however, were found to be associated with the Alu insertion. Further detailed genetic analysis demonstrated that at least eight haplotypes, including a new haplotype (L), were present in the Taiwanese population and that all DM1 alleles were with the same haplotype (haplotype $A$ ) as that identified in Canadian and Japanese DM1 populations. These findings support the notion that the out-of-Africa DM1 alleles were originated by stepwise expansion from a pool of large-sized normal chromosomes with haplotype A. European Journal of Human Genetics (2001) 9, $638-641$.

Keywords: CTG repeats; DM1; haplotype; founder effect; Taiwan

\section{Introduction}

Myotonic dystrophy type 1 (DM1; OMIN 160900) is an autosomal dominant disorder characterised by myotonia in conjunction with progressive weakening and wasting of skeletal muscle. ${ }^{1}$ DM1 is one of the genetic disorders exhibiting anticipation in families, ie, an increase in clinical severity and an earlier age of onset in successive generations,

*Correspondence: K-M Hsiao, Department of Life Sciences, Chung Shan Medical and Dental College, No.110, Sec.1, Chien-Kuo North Road, Taichung, Taiwan 402, Republic of China.

Tel: +1 886424730022 Ext. 1802; Fax: +1 8864 24723229;

E-mail: kmh@mercury.csmc.edu.tw

Received 20 February 2001; revised 24 April 2001; accepted 7 May 2001 due to the intergenerational expansion of (CTG)n in the $3^{\prime}$ untranslated region of the myotonic dystrophy type 1 protein kinase gene (DM1PK) on chromosome $19 .^{2}$ The array length of tandemly repeated CTGs in normal alleles is variable, with a copy-number range of 5-37, whereas, in DM1 alleles, the copy number usually is greater than 50 .

The prevalence of DM1 was found to be 2.2-5.5 in the Western European population ${ }^{1}$ and 5.5 in the Japanese population. ${ }^{3}$ However, a very low prevalence of DM1 in central and Southern Africans, Southern Chinese, and Thai was reported. ${ }^{4}$ The prevalence of DM1 in the population appeared to correlate with the frequency of large CTG repeats (>18 repeats) within the normal range. ${ }^{5-7}$ Therefore, in this study we investigated the frequency of those large-sized 
normal alleles in the Taiwanese population in an attempt to verify whether or not it correlates well with the low DM1 prevalence predicted.

It was also known that all DM1 chromosomes in the Canadian and Japanese populations were exclusively associated with the Alu insertion and seven additional single base polymorphic markers (haplotype A), ${ }^{8,9}$ suggesting a founder effect for the origin of myotonic dystrophy type 1 mutation. In the Africans, however, a reported DM1 chromosome was found to be associated with the haplotype D allele. ${ }^{10}$ In addition, a few normal chromosomes with more than $18 \mathrm{CTG}$ repeats were also found to be associated with the Alu deletion allele in other diverse ethnic populations. ${ }^{11,12}$ These findings raise the possibility that other non-A type DM1 alleles may be present in non-African DM1 populations as well. To investigate the genesis of the expansion mutation of Taiwanese DM1 chromosomes, we studied linkage disequilibrium between CTG repeats and the haplotypes. We confirm that the pathogenic expansions occur on chromosomes of haplotype A. However, we also find a different frequency distribution pattern of the haplotypes in the Taiwanese population compared with those defined in other ethnic populations. ${ }^{8,9}$

\section{Subjects and methods \\ Subjects}

The study of (CTG)n repeats frequency distribution and the Alu insertion/deletion polymorphism was performed using DNA samples from 248 unrelated, normal individuals and 17 DM1 patients. Haplotype analysis was performed in 42 nonDM1 and 12 DM1 Taiwanese families. The numbers of chromosome for which the haplotype could unequivocally be determined were 75 for non-DM1 and 13 for DM1 patients.

\section{Determination of (CTG)n repeat size}

Genomic DNA was isolated from peripheral blood leukocytes or lymphoblasts transformed with Epstein-Barr virus using Puregene DNA isolation kit (Gentra Systems, Minneapolis, MN, USA). (CTG)n repeat size of the normal as well as DM1 alleles was determined as described previously. ${ }^{13}$ Statistical values were calculated using the $\chi^{2}$ test in $2 \times 2$ tables with Yates' correction.

\section{Haplotype analysis}

The polymorphic markers used to construct haplotypes in this study were previously published. ${ }^{8,14,15}$ In a total of $20 \mu \mathrm{l}$ reaction, genomic DNA (100 ng) was PCR amplified with the appropriate primers $(0.375 \mu \mathrm{M})$ in the presence of $200 \mu \mathrm{M}$ each dNTP, $1 \times$ PCR buffer I, and $0.5 \mathrm{U}$ FailSafe ${ }^{\mathrm{TM}}$ PCR enzyme mix (Epicentre Technologies, Madison, WI, USA). For Hinfl-, BpmI-, and Fnu4HI-polymorphism, amplification was conducted for 40 cycles at $96^{\circ} \mathrm{C}$ for $0.5 \mathrm{~min}, 55^{\circ} \mathrm{C}$ for $1 \mathrm{~min}$, and $72^{\circ} \mathrm{C}$ for $1.5 \mathrm{~min}$. For DraIII-, BanI-, HhaI-, and TaqI-polymorphism, amplification was conducted for 40 cycles at $94^{\circ} \mathrm{C}$ for $0.5 \mathrm{~min}, 59^{\circ} \mathrm{C}$ for $1 \mathrm{~min}$, and $72^{\circ} \mathrm{C}$ for $1.5 \mathrm{~min}$. Amplified products were digested with appropriate restriction enzymes and were subsequently separated on $5 \%$ polyacrylamide gel for size determination.

\section{Results}

\section{(CTG)n allele distribution}

Frequency distribution of normal alleles with variable CTG repeat lengths in the DM1 locus was analysed for 496 chromosomes and the result is shown in Figure 1. Heterozygote frequency in the studied population is $78 \%$. A total of 18 alleles were found, ranging in size from 5 to 30 repeats. The most common allele had five CTG repeats (29\% of chromosomes). Repeat sizes for the majority of the remaining alleles (60.3\% of chromosomes) ranged from 11 to 14 , with 12 repeats being most frequent (25.4\%). In total, seven alleles $(1.4 \%)$ were found to have a repeat size larger than 18 repeats which may have significant instability for further expansions towards becoming DM1 alleles. ${ }^{9}$

\section{Haplotype analysis}

A total of 268 normal and 17 expanded DM1 chromosomes were ascertained for the association of CTG repeats and the $A l u$ insertion/deletion polymorphism (Table 1). Among the normal DM1 chromosomes, $90 \%(182 / 202)$ of the (CTG) $6-17$ alleles are associated with the $A l u$ deletion polymorphism. On the other hand, (CTG) $)_{5}$ alleles show a strong association with the Alu insertion polymorphism (92\%, 48/52). Although there were only three samples included, no association between the insertion allele and the (CTG) 19 alleles was observed. However, all of the expanded alleles show the absolute linkage disequilibrium with $A l u$ insertion polymorphism.

A more detailed genetic analysis consisting of (CTG)n as well as eight other polymorphic markers was then performed to investigate the association of certain (CTG)n repeat alleles and particular haplotypes. Our data demonstrate that all DM1 and two (CTG) ${ }_{25}$ alleles examined associate exclusively with haplotype A. A strong linkage disequilibrium between $(\mathrm{CTG})_{5}$ and haplotype A was also detected. Most of the (CTG) 8-19 $_{19}$ alleles associate with haplotypes A-D, with a frequency of $\mathrm{D}>\mathrm{C}>\mathrm{B}>\mathrm{A}$. On normal DM1 chromosomes, a total of eight different haplotypes, including a new haplotype (L) which has never been described in other populations, were identified. Table 2 shows the frequency of each haplotype in the Taiwanese population. Haplotype A is the most frequent one that appears in the Taiwanese people studied (41\%). Haplotypes B and J, which were observed either only in the Canadians or in the Japanese, both were found in the Taiwanese. Haplotypes E, H, I, and K were not found in this study. Although the frequency distribution of haplotypes seems to be different in diverse ethnic groups, haplotypes $\mathrm{A}-\mathrm{D}$ are the major ones and could have served as the founding haplotypes. 


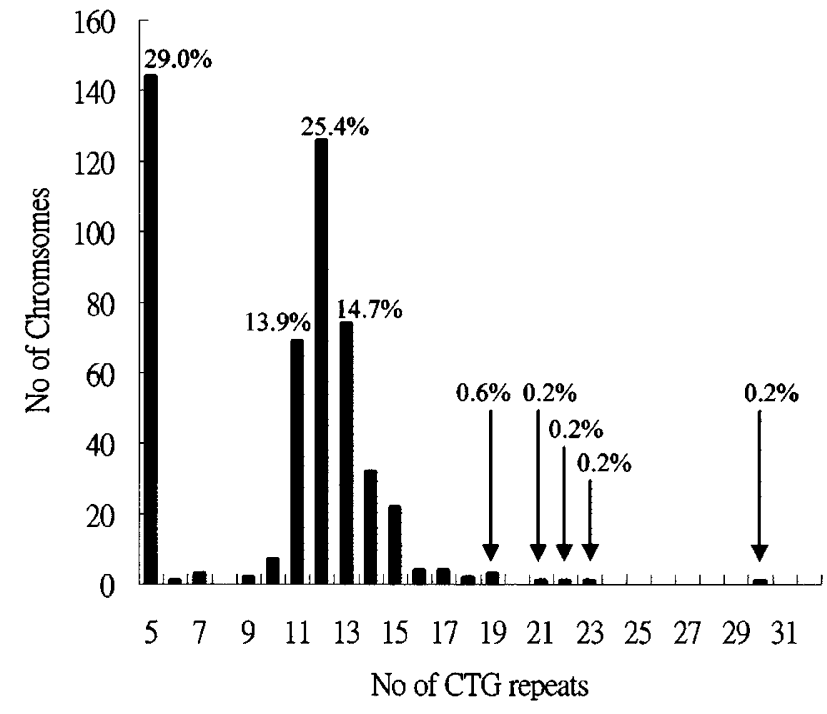

Figure 1 Distribution of CTG repeat sizes in the DM1PK gene in normal Taiwanese population. A total of 496 alleles were examined.

Table 1 Association of CTG repeats and the Alu insertion/ deletion polymorphism

\begin{tabular}{lrcc}
\hline CTG repeats & $\mathrm{n}$ & Alu insertion & Alu deletion \\
\hline 5 & 52 & 48 & 4 \\
6 & 1 & 0 & 1 \\
7 & 3 & 1 & 2 \\
9 & 2 & 0 & 2 \\
10 & 4 & 0 & 4 \\
11 & 40 & 5 & 35 \\
12 & 72 & 2 & 70 \\
13 & 49 & 6 & 43 \\
14 & 23 & 1 & 22 \\
15 & 13 & 2 & 11 \\
16 & 3 & 1 & 2 \\
17 & 2 & 2 & 0 \\
19 & 3 & 0 & 3 \\
30 & 1 & 1 & 0 \\
Expanded alleles & 17 & 17 & 0 \\
\hline
\end{tabular}

\section{Discussion}

In this study, we have demonstrated that the frequency of large CTG alleles in normal Taiwanese is low (Figure 1). This result suggests that the prevalence of DM1 in Taiwanese is much lower than those in the European and Japanese populations and may be close to that in the South African Negroids. ${ }^{3,5}$

The $(\mathrm{CTG})_{>16}$ alleles were previously shown to associate exclusively with the Alu insertion polymorphism and be passed on consistently in different ethnic populations. . $^{76,17}$ In this study, however, three (CTG) 19 alleles examined were associated with Alu deletion alleles. This is in contrast to a generally accepted proposal that the (CTG) $)_{5} / A l u$ insertion evolved to $(\mathrm{CTG})_{19}$ in a unique event. Our data raises the possibility that the Taiwanese population was founded before the Japanese and Caucasian populations diverged from a common ancestry and the Taiwanese (CTG) 19 alleles evolved from (CTG) $)_{1-14}$ alleles through a separate route. Alternatively, the (CTG) ${ }_{19} /$ Alu deletion simply arose from a $A l u$ deletion event on a founder Taiwanese (CTG) 19 chromosomes. Furthermore, the identification of haplotype L, a new haplotype unique to the Taiwanese population, indicates that genetic recombination happened within the DM1 locus. This haplotype could be generated through a recombination event between chromosomes with haplotype A and D (Table 2 ). These results suggested the possibility that certain unique haplotypes could have been developed in different ethnic populations by recombination events in normal or DM1 chromosomes.

We have demonstrated that all Taiwanese DM1 chromosomes examined were of haplotype A. Our findings provide the first molecular evidence for the founder effect of DM1 mutations in Taiwan. It is likely that the Taiwanese, and maybe all non-African, DM1 chromosomes could have originated from a pool of large-sized normal alleles with haplotype A which was generated after migration out of Africa. The only DM1 family observed in Nigerian people was probably derived from a very rare, individual mutation event.

Table 2 Haplotype frequency in DM1 and non-DM1 Taiwanese individuals

\begin{tabular}{|c|c|c|c|c|c|c|c|c|c|c|c|}
\hline \multirow[b]{2}{*}{ Haplotype } & \multirow{2}{*}{$\begin{array}{l}\text { Drall! } \\
\text { (N9) }\end{array}$} & \multirow{2}{*}{$\begin{array}{l}\text { HphI } \\
\text { (Intron 4) }\end{array}$} & \multirow{2}{*}{$\begin{array}{l}\text { Hhal } \\
\text { (Intron 5) }\end{array}$} & \multirow{2}{*}{$\begin{array}{l}\triangle 1 k b \\
\text { (Intron 8) }\end{array}$} & \multirow{2}{*}{$\begin{array}{l}\text { HinfI } \\
\text { (Intron 9) }\end{array}$} & \multirow{2}{*}{$\begin{array}{l}\text { Bpm/ } \\
\text { (Exon 10) }\end{array}$} & \multirow{2}{*}{$\begin{array}{l}\text { Fnu4HI } \\
\text { (Intron 11) }\end{array}$} & \multirow{2}{*}{$\begin{array}{l}\text { Taql } \\
\text { (D19S463) }\end{array}$} & \multicolumn{3}{|c|}{ Haplotype frequency (\%) } \\
\hline & & & & & & & & & Canadian $^{8}$ & Japanese & Taiwanese \\
\hline DM & 1 & 2 & 1 & 1 & 2 & 2 & 1 & 2 & 100 & 100 & 100 \\
\hline A & 1 & 2 & 1 & 1 & 2 & 2 & 1 & 2 & 49 & 30 & 41 \\
\hline B & 2 & 2 & 2 & 2 & 1 & 2 & 2 & 1 & 27 & 0 & 11 \\
\hline C & 1 & 1 & 2 & 2 & 1 & 1 & 2 & 1 & 16 & 10 & 15 \\
\hline $\mathrm{D}$ & 1 & 2 & 2 & 2 & 1 & 2 & 2 & 1 & 8 & 53 & 21 \\
\hline$E$ & 2 & 2 & 2 & 2 & 1 & 2 & 2 & 2 & $<1$ & 0 & 0 \\
\hline $\mathrm{F}$ & 1 & 1 & 2 & 2 & 1 & 2 & 2 & 1 & $<1$ & 0 & 2.6 \\
\hline$G$ & 1 & 2 & 1 & 1 & 2 & 1 & 1 & 2 & $<1$ & $<1$ & 4.0 \\
\hline $\mathrm{H}$ & 2 & 2 & 2 & 2 & 2 & 2 & 2 & 2 & $<1$ & 0 & 0 \\
\hline I & 1 & 1 & 2 & 2 & 2 & 2 & 1 & 1 & $<1$ & 0 & 0 \\
\hline J & 1 & 2 & 2 & 2 & 1 & 1 & 2 & 1 & 0 & 4.8 & 4.0 \\
\hline K & 1 & 2 & 1 & 1 & 2 & 2 & 1 & 1 & 0 & 1.3 & 0 \\
\hline $\mathrm{L}$ & 1 & 2 & 2 & 2 & 2 & 2 & 1 & 2 & 0 & 0 & 1.3 \\
\hline
\end{tabular}




\section{Acknowledgments}

We are grateful to the normal and DM1 volunteers for their cooperation; Dr. Chuan Li for the valuable comments. This work was supported by grants from the National Science Council of the Republic of China (NSC 89-2320-B040-068 and NSC89-2320-B040-063), the Chung Shan Medical and Dental College Research Fund CSMC-89-OM-A-075.

\section{References}

1 Harper PS: Myotonic dystrophy. 2nd edn. WB Saunders: London, 1989.

2 The international Myotonic dystrophy Consortium (IDMC): New nomenclature and DNA testing guidelines for myotonic dystrophy type 1 (DM1). Neurology 2000; 54: 1218-1221.

3 Davies J, Yamagata H, Shelbourne P et al: Comparison of the myotonic dystrophy associated CTG repeat in European and Japanese populations. J Med Genet 1992; 29: 766-769.

4 Ashizawa T, Epstein HF: Ethnic distribution of the myotonic dystrophy gene. Lancet 1991; 338: 642-643.

5 Goldman A, Ramsay M, Jenkins T: Absence of myotonic dystrophy in southern African Negroids is associated with a significantly lower number of CTG trinucleotide repeats. J Med Genet 1994; 31: 37-40.

6 Mor-Cohen R, Magal N, Gadoth N, Shohat T, Shohat M: Correlation between the incidence of myotonic dystrophy in different groups in Israel and the number of CTG trinucleotide repeats in the myotonin gene. Am J Med Genet 1997; 71: 156159.

7 Gennarelli M, Pavoni M, Cruciani F, De Stefano G, Dallapiccola B, Novelli G: CTG repeats distribution and Alu insertion polymorphism at myotonic dystrophy (DM) gene in Amhara and Oromo populations of Ethiopia. Hum Genet 1999; 105: $165-167$.

8 Neville CE, Mahadevan MS, Barcelo JM, Korneluk RG: High resolution genetic analysis suggests one ancestral predisposing haplotype for the origin of the myotonic dystrophy mutation. Hum Mol Genet 1994; 3: 45-51.
9 Yamagata H, Nakagawa M, Johnson K, Miki T: Further evidence for a major ancient mutation underlying myotonic dystrophy from linkage disequilibrium studies in the Japanese population. J Hum Genet 1998; 43: 246-249.

10 Krahe R, Eckhart M, Ogunniyi AO, Osuntokun BO, Siciliano MJ, Ashizawa T: De novo myotonic dystrophy mutation in a Nigerian kindred. Am J Hum Genet 1995; 56: 1067 - 1074.

11 Rubinsztein DC, Leggo J, Amos W, Barton DE, Ferguson-Smith MA: Myotonic dystrophy CTG repeats and the associated insertion/deletion polymorphism in human and primate populations. Hum Mol Genet 1994; 3: 2031-2035.

12 Tishkoff SA, Goldman A, Calafell F et al: A global haplotype analysis of the myotonic dystrophy locus: implications for the evolution of modern humans and for the origin of myotonic dystrophy mutations. Am J Hum Genet 1998; 62: 1389-1402.

13 Hsiao KM, Lin HM, Pan H et al: Application of FTA ${ }^{\circledR}$ sample collection and DNA purification system on the determination of CTG trinucleotide repeat size by PCR-based Southern blotting. J Clin Lab Anal 1999; 13: 188-193.

14 Mahadevan MS, Foitzik MA, Surh LC, Korneluk RG: Characterization and polymerase chain reaction (PCR) detection of an Alu deletion polymorphism in total linkage disequilibrium with myotonic dystrophy. Genomics 1993; 15: 446-448.

15 Mahadevan MS, Amemiya C, Jansen G et al: Structure and genomic sequence of the myotonic dystrophy (DM kinase) gene. Hum Mol Genet 1993; 2: 299-304.

16 Yamagata H, Miki T, Nakagawa M, Johnson K, Deka R, Ogihara T: Association of CTG repeats and the 1-kb Alu insertion/deletion polymorphism at the myotonin protein kinase gene in the Japanese population suggests a common Eurasian origin of the myotonic dystrophy mutation. Hum Genet 1996; 97: 145-147.

17 Imbert G, Kretz C, Johnson K, Mandel J-L: Origin of the expansion mutation in myotonic dystrophy. Nature Genet 1993; 4: $72-76$. 